\title{
Carbon bubble toil and trouble
}

\author{
Even if some sceptics consider climate science akin to witchcraft and politicians pursue ineffective \\ policies, private enterprise is beginning to take climate change seriously.
}

Climate protection requires no magic solutions, but it does require boldness and resolve from policy makers. Instead, what we have is the kind of political timidity that often results when politicians perceive a significant chance of policy failure and of having to take the rap if things go wrong. Paul Harris (page 245) considers whether 'blame aversion' could actually underlie the inadequacy of present climate policies, which have so far failed to reduce global greenhouse gas emissions.

If today's generation of politicians are laggards when it comes to looking after the climate, perhaps private enterprise will come to the rescue. In this regard, Sonja van Renssen (page 241) explains how, on the issue of climate change, some investors are taking matters into their own hands, effectively outpacing policymakers in driving towards a cleaner world by choosing where they put their money. It seems that an increasing number of perfectly hard-nosed financiers and investment managers are coming round to the view that investing in low-carbon technology and infrastructure makes good financial sense.

In addition, major players in the financial markets are becoming increasingly uneasy about the extent of the impact of future climate policies on power companies. A supposition - fostered by the Carbon Tracker Initiative - is that fossil fuels may be nowhere near as profitable in the future as they have been so far. This is not simply because the costs of prospecting and drilling for oil, for example, are increasing, or that the fossil fuel resources that give the oil, coal and natural gas companies their value are about to run out - they are not. The problem is more that a large portion perhaps as much as 80 per cent - of these reserves will have to be left untouched if society has any chance of limiting global temperature rise to $2{ }^{\circ} \mathrm{C}$ this century.

By consistently overvaluing the fossil fuel assets of companies, the argument goes, the world's financial markets are with gusto busily inflating a 'carbon bubble', which, if burst, could spell ruin for investors. It is no surprise then that individuals, corporations and pension fund holders are beginning to wakeup to the risk and either starting to divest from fossil fuels or seriously considering it.

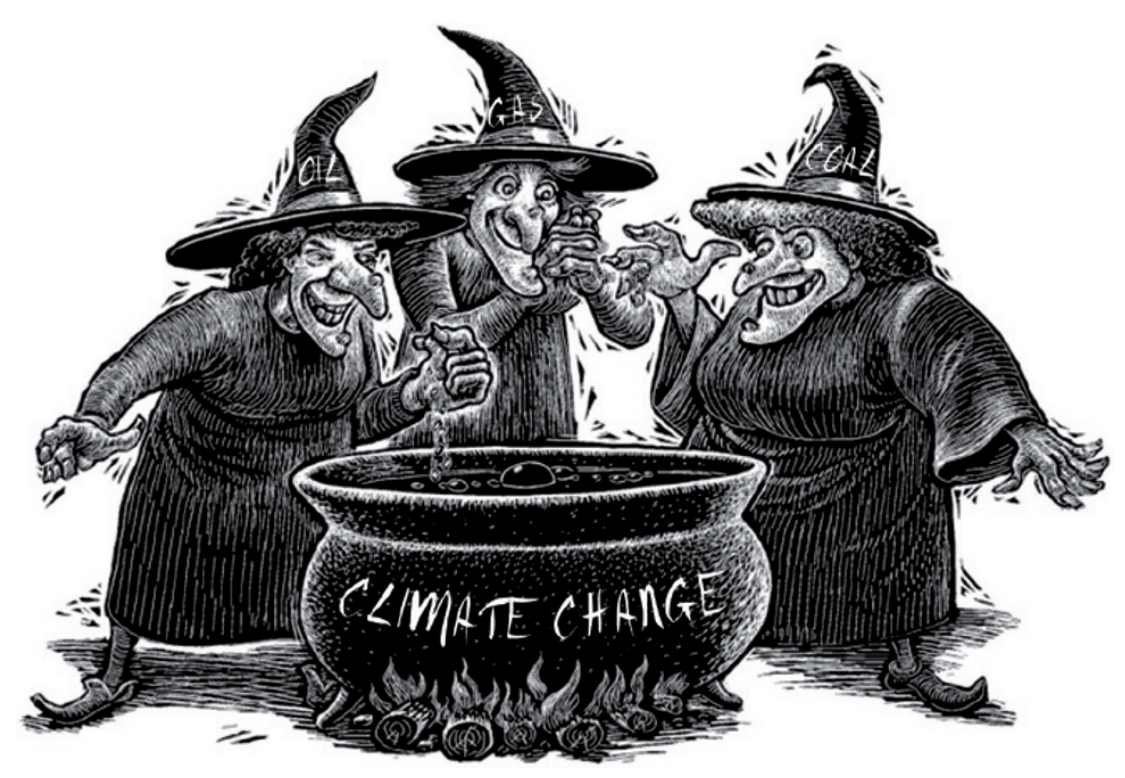

Even the World Bank has stopped lending for new coal-fired power plants.

However, as discussed by van Renssen, it does not automatically follow that money divested from fossil fuels will be rechannelled into cleaner activities. Government policies must incentivize and support investment in renewables and energy efficiency projects. Otherwise, money taken out of fossil fuels could just as easily find its way into other carbon-intensive sectors of the economy. However, as noted in the article, large institutional investors such as those managing pension funds now see positive benefits in green investment and are likely to be in the vanguard of change.

However, there are risks. On page 237, Tobias Schmidt - an expert on public policy and regulation in the energy sector cautions that although only the mobilization of private capital can realistically provide the infrastructure development and wholesale uptake of new and cleaner technologies needed for effective climate change mitigation, such investments can be risky, especially in developing counties.

Schmidt argues that one important way that policymakers can encourage private low-carbon investments is to decrease the downside risk through a process called 'de-risking'. Essentially this entails taking action to reduce the danger of some untoward event causing major financial loss, and generally seeking to make business plans more robust in the face of such eventualities. One obvious way that this can be done is to spread risk, for example through the insurance markets, or by using public institutions such as development banks to underwrite potential losses. Another way is by improving local institutions to reduce the chances of losses through construction delays, for example.

To improve understanding of risk and derisking, Schmidt proposes the establishment of a global database on financing costs and other important information that would-be investors need to make better informed decisions. He also advocates more research on the factors that drive financing costs, especially in developing nations, as well as the systematic evaluation of the effectiveness and efficiency of de-risking measures.

Finally, Schmidt encourages researchers over the coming years to develop workable policy recommendations aimed at maximizing the leverage of de-risking in creating conditions conducive to low-carbon investment.

So perhaps an alliance of enlightened politicians, businesspeople and institutional supporters will yet achieve a global lowcarbon economy and avoid the tragedy of errors that so many scientists believe will result in dangerous climate change. 